\title{
BMJ Open Trends, variations and prediction of staff sickness absence rates among NHS ambulance services in England: a time series study
}

\author{
Zahid B Asghar (D) , ${ }^{1}$ Paresh Wankhade, ${ }^{2}$ Fiona Bell, ${ }^{3}$ Kristy Sanderson (D) , ${ }^{4}$ \\ Kelly Hird, ${ }^{3}$ Viet-Hai Phung, ${ }^{1}$ Aloysius Niroshan Siriwardena (i) ${ }^{1}$
}

To cite: Asghar ZB, Wankhade P, Bell F, et al. Trends, variations and prediction of staff sickness absence rates among NHS ambulance services in England: a time series study. BMJ Open 2021;0:e053885. doi:10.1136/ bmjopen-2021-053885

- Prepublication history and additional supplemental material for this paper are available online. To view these files, please visit the journal online (http://dx.doi.org/10.1136/ bmjopen-2021-053885).

Received 29 May 2021 Accepted 13 September 2021

Check for updates

(c) Author(s) (or their employer(s)) 2021. Re-use permitted under CC BY-NC. No commercial re-use. See rights and permissions. Published by BMJ.

${ }^{1}$ Community and Health Research Unit, Lincoln Medical School, School of Health and Social Care, University of Lincoln-Brayford Campus, Lincoln, UK

${ }^{2}$ Business School, Edge Hill University, Ormskirk, Liverpool, UK

${ }^{3}$ Yorkshire Ambulance Service NHS Trust, Wakefield, UK

${ }^{4}$ School of Health Sciences, University of East Anglia, Norwich, UK

Correspondence to Dr Zahid B Asghar; zasghar@lincoln.ac.uk

\section{ABSTRACT}

Objectives Our aim was to measure ambulance sickness absence rates over time, comparing ambulance services and investigate the predictability of rates for future forecasting.

Setting All English ambulance services, UK.

Design We used a time series design analysing published monthly National Health Service staff sickness rates by gender, age, job role and region, comparing the 10 regional ambulance services in England between 2009 and 2018. Autoregressive Integrated Moving Average (ARIMA) and Seasonal ARIMA (SARIMA) models were developed using Stata V.14.2 and trends displayed graphically.

Participants Individual participant data were not available. The total number of full-time equivalent (FTE) days lost due to sickness absence (including non-working days) and total number of days available for work for each staff group and level were available. In line with The Data Protection Act, if the organisation had less than 330 FTE days available during the study period it was censored for analysis.

Results A total of 1117 months of sickness absence rate data for all English ambulance services were included in the analysis. We found considerable variation in annual sickness absence rates between ambulance services and over the 10-year duration of the study in England. Across all the ambulance services the median days available were 1336888 with IQR of 548796 and 73346 median days lost due to sickness absence, with IQR of 30551 days. Among clinical staff sickness absence varied seasonally with peaks in winter and falls over summer. The winter increases in sickness absence were largely predictable using seasonally adjusted (SARIMA) time series models. Conclusion Sickness rates for clinical staff were found to vary considerably over time and by ambulance trust. Statistical models had sufficient predictive capability to help forecast sickness absence, enabling services to plan human resources more effectively at times of increased demand.

\section{INTRODUCTION}

Ambulance services in England have the highest level of sickness absence rates compared with other healthcare organisations in the UK National Health Service
Strengths and limitations of this study

- Sickness absence data are limited and there is variation in recording of data among ambulance services, the seasonal modelling is limited to professionally clinically qualified ambulance staff due to missing and incomplete data in other staff groups.

- Reasons for sickness absence across ambulance trusts are poorly reported or recorded, and a lack of gender and age information were further imitations.

- This was an analysis across and entire public ambulance clinical workforce in England over multiple years.

- Predictive models can help to forecast sickness absence in a wider variety of health settings, leading to resource planning and potential financial savings.

(NHS) ${ }^{1}$ Against the national average absence rate of $4.3 \%$ over an 8-year period (data available since 2009), ambulance staff showed an average absence rate of $6.2 \%$ with year-onyear increases. An independent review ${ }^{2}$ estimated that a $1 \%$ reduction in staff absence could save the ambulance Trusts $£ 15$ million per year.

Systematic analysis of sickness absence in ambulance services is lacking despite staff health and well-being having been identified as a key priority among all NHS employees. ${ }^{3}$ An early study examining sickness absence in West Midlands Metropolitan Ambulance Service compared with the Post Office and Fire Service in the $1980 \mathrm{~s}^{4}$ found that musculoskeletal injury was the main cause of sickness absence and this was exacerbated by the nature of ambulance work. Sickness absence has been highlighted as a concern for health in ambulance services ${ }^{56}$ but detailed reasons for this and potential solutions are needed.

Previous research suggests that high rates of mental health problems including burn-out, substance misuse and suicide in emergency 
ambulance workers, which may highlight occupationspecific stressors and health-related sequelae. ${ }^{7-9}$ In a survey by the charity Mind of over 1300 UK ambulance service responders, problems at work including excessive workload, pressure from management, long hours, changing shift patterns and exposure to traumatic incidents, were often cited as the main cause of mental health problems. ${ }^{10}$ While reasons for absence are not included in reported figures, a previous study identified that mental health problems were in the top three reasons for sickness absence in the $\mathrm{NHS}^{2}$ and has been identified as a key area for action. ${ }^{11}$

Our aim was to measure ambulance sickness absence rates over time, comparing ambulance services and investigating the predictability of rates.

\section{METHODS}

\section{Study design and data}

We used a time series design analysing published NHS staff sickness rates by gender, age, job role and region comparing the ten ambulance services in England. Data were specifically requested and provided by NHS Digital for this study. The dataset included sickness absence rates for NHS ambulance staff calculated from the electronic staff record (ESR). Rates were obtained by dividing the 'Full Time Equivalent (FTE) Number of Days Sick' by the 'FTE Number of Days Available' from the absence dimension on the ESR Data Warehouse which gave the following information: FTE days available, FTE days lost, sickness absence rate by staff group, qualification level and ambulance trust for October to September for the 10-year period from 2009 to 2018. In line with The Data Protection Act, if the organisation had less than 330 FTE days available during the study period it was censored for analysis. Ambulance Trusts were randomly assigned an alphabetical letter (A-J) to protect confidentiality of individual trusts where higher or lower rates are apparent. While there is some merit in naming individual services, our approach was to present the data anonymously to the participating trusts for a shared learning.

Positivistic theory underpinning the analysis is that future trends can be predicated from the past ${ }^{12}$ provided that the variation is not large and that suitable parameters such as well-being and sickness are a good proxy to capture the sickness absence trend.

\section{Statistical analysis}

Initial analysis was performed using Stata V.14.2, and subsequent analysis for forecasting was done in Wolfram Mathematica V.11.3. The Autoregressive Moving Average (ARMA) is based on taking the previous linear incidence termed autogressive together with the linear moving average which considers the current and previous residual time series. We used the Box-Jenkins method of Autoregressive Integrated Moving Average (ARIMA), where a univariate time series model is based on the generalised model of ARMA with a differencing process which converts non-stationary (seasonally variable) data to stationary data. The differencing is a measure of how many non-seasonal differences are needed to achieve stationarity, if there is no differencing then we simply revert back to ARMA.

As there was strong evidence of seasonality within our data, Seasonal ARIMA (SARIMA) models were also used. SARIMA models are based on the ARIMA model but include seasonal differencing, where periodicity within the dataset is accounted for. We focused the model on sickness absence in clinical staff groups which included professionally qualified clinical staff (Hospital and Community Health Service (HCHS) doctors; Ambulance Paramedic; Ambulance Technician; Emergency Care Practitioner; Manager; Medical Technical Officers (MTO) /technician; nurse; other senior technicians (ST) and technician manager (TM); scientist; tutor)

We used the auto correlation functions (ACF) to determine whether seasonality was present (non-stationarity) within the model or not, that is, we measured the amount of linear dependence between observations separated by a lag and the partial autocorrelation function (PAF) determined the number of autoregressive terms. If the ACF and the PAF showed points outside the acceptance value then this was taken to indicate seasonality within the time series, requiring the use of SARIMA model.

Akaike information criterion (AIC), Bayesian information criterion (BIC) or Schwarz Bayesian criterion (SBC) likelihood values were calculated but AIC was used for model selection.

\section{Patient and public involvement}

There was no patient or public involvement in the study.

\section{RESULTS}

A total of 1117 months of sickness absence rate data for all English ambulance services were included in the analysis. Across all the ambulance services the median days available were 1336888 with IQR of 548796 and 73346 median days lost due to sickness absence, with IQR of 30551 days. The sample size of months for individual ambulance services was the same $(\mathrm{N}=109)$, except ambulance service trust I where data were only available until November $2016(\mathrm{~N}=76)$. For model validation, 6 months data were used to compare model forecasts. We found considerable variation in annual sickness absence rates among all clinical staff across each ambulance service in England and over the 10 years between 2009 and $2018^{1}$ (figure 1). Within an organisation, ambulance sickness absence rates do not vary greatly over time, with the exception of ambulance service $\mathrm{G}$, where a drop of $3.2 \%$ absence between the annual averages in 2010 and 2018 was observed. Figure 1 illustrates that this reduction in absence, the rate is sustained in subsequent years. There is also a slight drop in in average rates across all the ambulance services; this drop is still persistent when the outlier ambulance service is removed. 


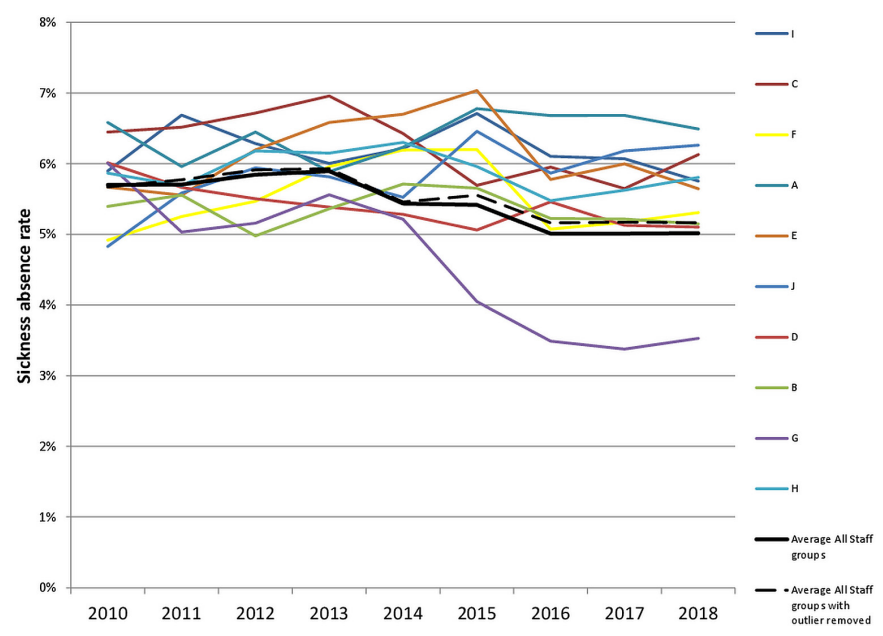

Figure 1 Annual sickness absence rates for all clinical staff in each (A-J) NHS ambulance service in England. NHS, National Health Service.

Further analysis of variation in absence data for professionally qualified clinical staff (HCHS doctors; ambulance paramedic; ambulance technician; emergency care practitioner; manager; MTO/technician; nurse; other ST\&TM; scientist; tutor) was carried out.

Models ARIMA or SARIMA were developed and selected based on information criteria which estimated prediction errors of the models for the given ambulance service data including AIC, BIC or SBC likelihood values. Lower values indicated higher quality of fit and therefore the model with lowest values was selected. SARIMA models were selected because of seasonality in the data; most services showed differences between ARIMA and SARIMA model statistics, but this was less so for ambulance service I (table 1).

We present graphs showing sickness absence rates for clinical staff in individual ambulance services at monthly

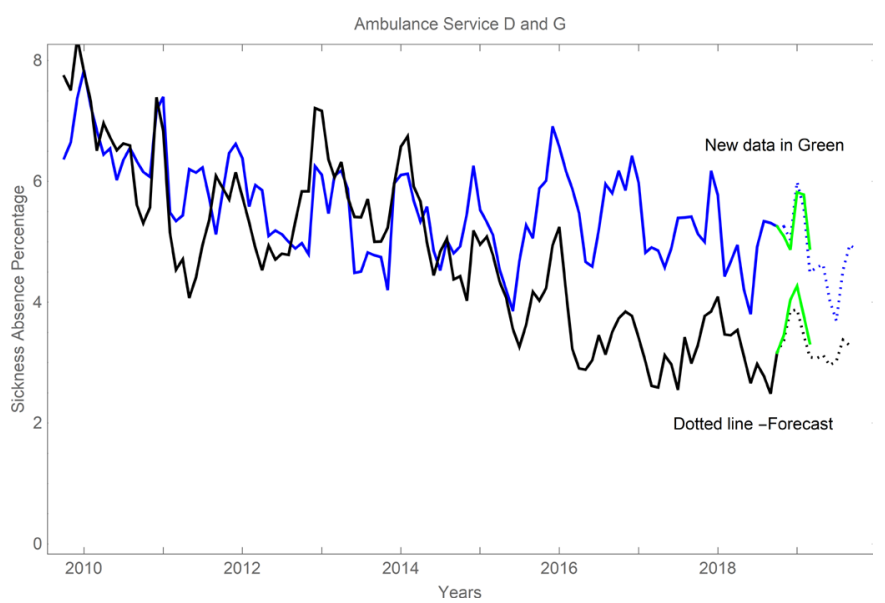

Figure 2 Sickness absence rates over time (2009-2018) for ambulance services D (blue line) and $G$ (black line) with forecasted (dotted lines, 12 months period). Solid green line shows new data rates for the period 1 October 2018 to 1 March 2019.

intervals between 2009 and 2018. We forecast rates for 2019 based on the SARIMA models shown as dotted lines. We then obtained data for 2019 where actual rates for the year are shown as different coloured solid lines and compared the actual and predicted graphs. Predicted values corresponded well for services $\mathrm{D}, \mathrm{E}, \mathrm{G}$ and $\mathrm{H}$ (figures 2 and 3).

Trusts $\mathrm{E}$ and $\mathrm{H}$ had similar means and SD, models predicted the seasonality and trends well. Although both ambulance trusts A and G had the largest SDs (table 2), trust $\mathrm{G}$ had better model fit. Trusts $\mathrm{C}$ and $\mathrm{I}$ are shown in (table 3). Trusts D and G showed clear decline in sickness absence trend. Forecasted sickness absence rates were higher than actual rates for services I (figure 4) and C (figure 5), 95\% CIs around forecasts suggest that predictions are still within range of acceptance. Trusts

Table 1 Model fit tests for each ambulance service

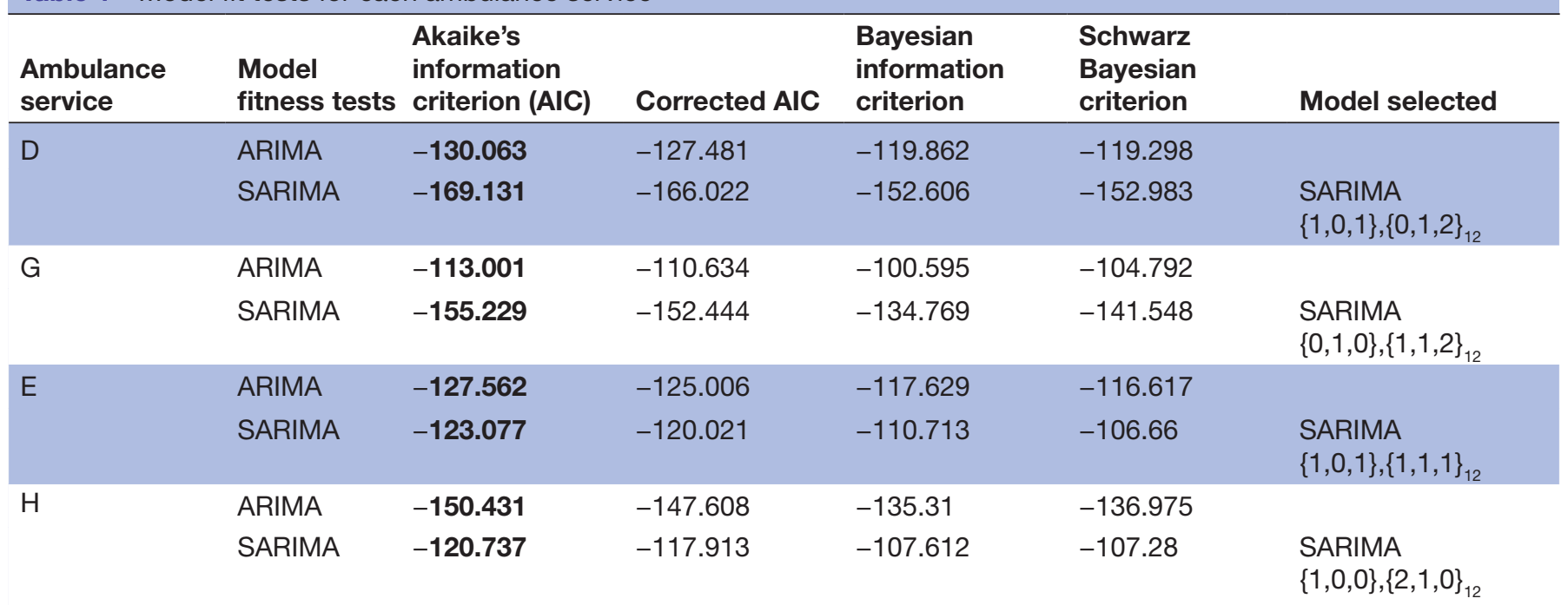

AIC shown in bold was used for model selection.

ARIMA, autoregressive integrated moving average; SARIMA, seasonal ARIMA. 


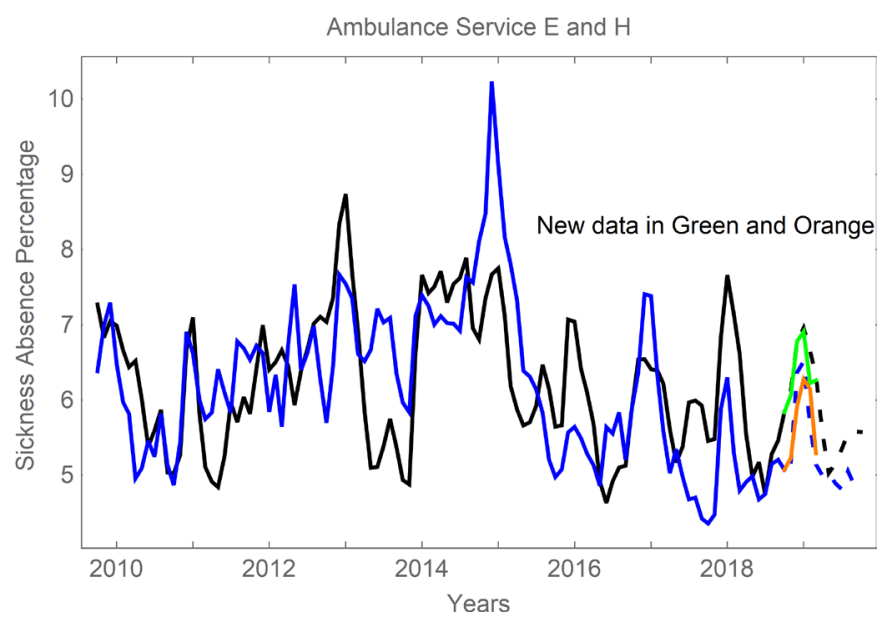

Figure 3 Sickness absence rates over time (2009-2018) with forecast (dotted line) and actual rates for 2019 (solid line) for ambulance services $\mathrm{E}$ (blue line) and $\mathrm{H}$ (black line). Solid green (service $\mathrm{H}$ ) and solid orange (service $\mathrm{E}$ ) lines show new data for the period 1 October 2018 to 1 March 2019.

A (figure 6), B (figure 7) and $\mathrm{J}$ (figure 8) are shown in online supplemental appendix 1 , table 1 .

\section{DISCUSSION}

\section{Main findings}

This is the first study to analyse published NHS staff sickness absence data for ambulance services. We found that sickness absence rates varied over time and by ambulance service, showing seasonal variation and predictability using seasonally adjusted (SARIMA) time series models which helped to predict future sickness absence rates. This model has been used widely in many disciplinary fields including forecasting epidemiological surveillance data ${ }^{13}$ and hospital visits. ${ }^{14}$ These models generally provide a good fit for processes that exhibit stationary means and do not show covariance over time.

For one ambulance trust, the absence rate varied monthly between $2.97 \%$ and $6.49 \%$ during second

Table 2 Mean sickness absence rate and SD for each ambulance service

\begin{tabular}{|c|c|c|c|}
\hline Ambulance service & $\mathbf{N}$ & Mean $(95 \% \mathrm{Cl})$ & SD \\
\hline A & 109 & 7.35 (7.07 to 7.62$)$ & 1.43 \\
\hline $\mathrm{B}$ & 109 & 5.61 (5.46 to 5.77 ) & 0.82 \\
\hline C & 109 & 7.19 (6.97 to 7.42$)$ & 1.19 \\
\hline $\mathrm{D}$ & 109 & 5.57 (5.42 to 5.73$)$ & 0.81 \\
\hline $\mathrm{E}$ & 109 & 6.2 (6.00 to 6.40$)$ & 1.06 \\
\hline $\mathrm{F}$ & 109 & 5.86 (5.71 to 6.00$)$ & 0.77 \\
\hline G & 109 & 4.82 (4.55 to 5.09$)$ & 1.41 \\
\hline $\mathrm{H}$ & 109 & 6.24 (6.06 to 6.41$)$ & 0.91 \\
\hline 1 & 76 & 7.28 (7.05 to 7.52$)$ & 1.01 \\
\hline $\mathrm{J}$ & 109 & 6.25 (6.06 to 6.44$)$ & 1.00 \\
\hline
\end{tabular}

Trusts $A$ and $G$ (bold) show the largest standard deviations. quarter of 2018. This may have been because of inaccuracies in data, organisational changes affecting sickness rates or other unknown reasons which need to be investigated further.

A clear pattern emerged of seasonal variation in sickness absence rates which peaked during January and February and then showed a drop before climbing again in the autumn months of October and November. This was an important finding which should be explored in other NHS organisational groups, including hospital and primary care. In the case of two ambulance trusts ( $\mathrm{F}$ and $\mathrm{G}$ in figure 1), a sustained drop in absence was noted from 2015 but seasonal variation in sickness absence persists. Reasons for the absences were not available so the impact of interventions cannot be determined. The models were able to predict future sickness absence rates for individual ambulance services and may therefore be used as a tool for workforce management.

This is a first study to analysis across and entire public ambulance clinical workforce in England over multiple years. We have shown that within an organisation, ambulance sickness absence rates do not vary greatly over time and that predictive models can help to forecast sickness absence in healthcare setting.

There were several limitations to this study. The first is that it was based on data for some clinical ambulance staff, but excluded those in the support staff category, because of missing and incomplete data. The second limitation is the lack of availability of data for gender and age of staff or the reasons for absence, although reported absence reasons are generally not well recorded. ${ }^{2}$ Although these models can capture some of the underlying dynamics of trusts, there are many complex organisational, economic, environmental, social and political changes which can make prediction difficult. These include urgent and emergency care service reconfigurations, changes to operational delivery models through contracting arrangements for non-emergency patient transfer and 111 services, changes to commissioning and consequent budget changes in the face of increasing demand for emergency care. ${ }^{2}$

Some of models did not predict as wells as others, this needs further investigation as these parsimony simple models may not be capturing all of the heterogeneities relating to the services, we are aware that there were some structural changes taking place as well as recruitment drives could create slightly more troughs or peaks out of sync with the model predictions. The COVID-19 pandemic will be likely to alter the patterns of absence during 2020-2021, but it is not clear if the seasonality in this staff cohort will be re-established once vaccines efficacy and policies that reduce requirements for quarantine take effect.

\section{Findings in relation to previous research}

Seasonal variation has been noted in a previous study of sickness absence in NHS workers, with rates in doctors peaking during December to January and lowest during 
Table 3 Model fits with $95 \%$ Cls showing variation in prediction over 12 months

\begin{tabular}{|c|c|c|c|c|c|c|}
\hline $\begin{array}{l}\text { Ambulance } \\
\text { service }\end{array}$ & $\begin{array}{l}\text { Model fitness } \\
\text { tests }\end{array}$ & $\begin{array}{l}\text { Akaike's } \\
\text { information } \\
\text { criterion (AIC) }\end{array}$ & Corrected AIC & $\begin{array}{l}\text { Bayesian } \\
\text { information } \\
\text { criterion }\end{array}$ & $\begin{array}{l}\text { Schwarz } \\
\text { Bayesian } \\
\text { criterion }\end{array}$ & $\begin{array}{l}\text { Model } \\
\text { selected }\end{array}$ \\
\hline \multirow[t]{2}{*}{ C } & ARIMA & -90.1803 & -87.5977 & -77.4113 & -79.4149 & \\
\hline & SARIMA & -116.747 & -113.923 & -100.169 & -103.29 & $\begin{array}{l}\text { SARIMA } \\
\{1,0,0\},\{1,1,1\}_{12}\end{array}$ \\
\hline I & ARIMA & -47.7445 & -45.1811 & -40.9185 & -40.7523 & \\
\hline
\end{tabular}

AIC shown in bold was used for model selection.

ARIMA, autoregressive integrated moving average; SARIMA, seasonal ARIMA.

August but with smaller differences between highest and lowest rates $(1.0 \%-1.3 \%)$ compared with ambulance staff (up to $3.5 \%$ monthly).

Minor respiratory illnesses, frequent during winter, are the most common cause of sickness absence across all UK workers, accounting for a quarter of days lost. ${ }^{15}$ One previous study, of US civil servants, found that seasonal trends were very predictable and suggested that specific causes could be targeted to reduce sickness absence. ${ }^{16}$ In another study, effectiveness of early sickness absenteeism intervention for seasonal/pandemic influenza seasonal variation has shown interesting results. ${ }^{17}$

Long-term sickness is more likely to be related to musculoskeletal and mental health problems and these are the costliest sources of sickness absence. ${ }^{18}$ In paramedics and Emergency Medical Technicians, back pain is the most common musculoskeletal condition, with back injuries and contusions, falls, slips and trips often caused in healthcare by to overexertion or when lifting patients. ${ }^{19}$ Numerous studies indicate ambulance and staff have high rates of post-traumatic stress, anxiety and burn-out ${ }^{2021}$ associated with lack of support, time pressures and physical demands of the role. ${ }^{8}$

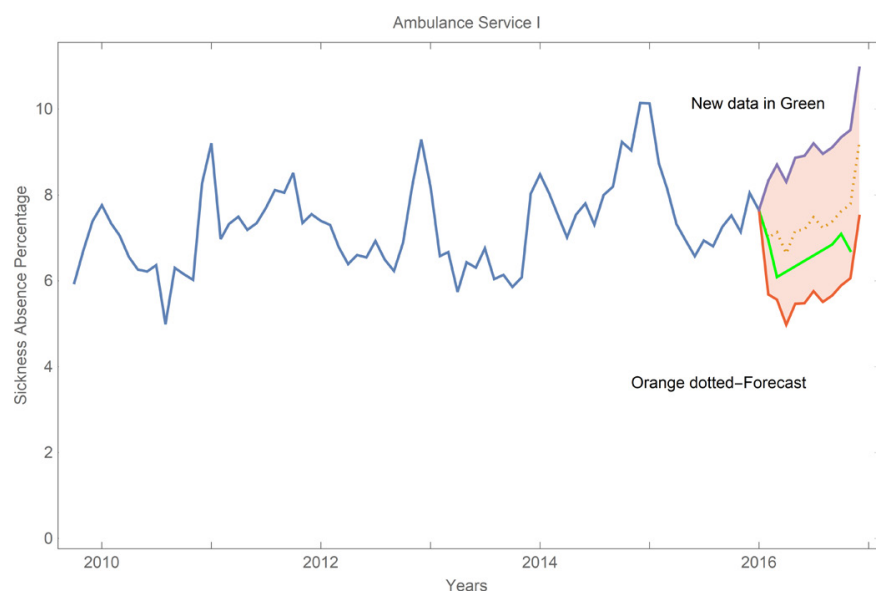

Figure 4 Sickness absence rates over time (2009-2018) with forecast (orange dotted line) and actual rates for 2019 (blue and green solid lines) for ambulance service I. The shaded area represents the $95 \%$ forecast Cls for 12 months prediction.
Implications for policy, practice and research

Accurately predicting sickness absence may help healthcare organisations plan for the expected winter peaks. Other seasonal infections such as norovirus ('winter vomiting virus') can affect both staff and patients at huge cost. $^{22}$ Winter illnesses such as influenza and other viral infections may lead to presenteeism, reducing quality of work, increasing time to recover and worsening the risk of cross infection, ${ }^{23}$ with influenza vaccination known to reduce winter sickness absence. ${ }^{24}$

Although the reasons for variation in sickness absence across ambulance trusts is poorly understood, the finding that the trust with the lowest rate had half that of the highest suggests that sustained reduction in reported absence can be achieved. However, whether this resulted from implementing well-being initiatives or other factors such as leadership styles, culture and levels of resourcing in those trusts with lower absence rates requires further empirical scrutiny. ${ }^{25}$

Simmons et al conducted a systematic review investigating randomised controlled trials of interventions to reduce sickness absence among healthcare workers and

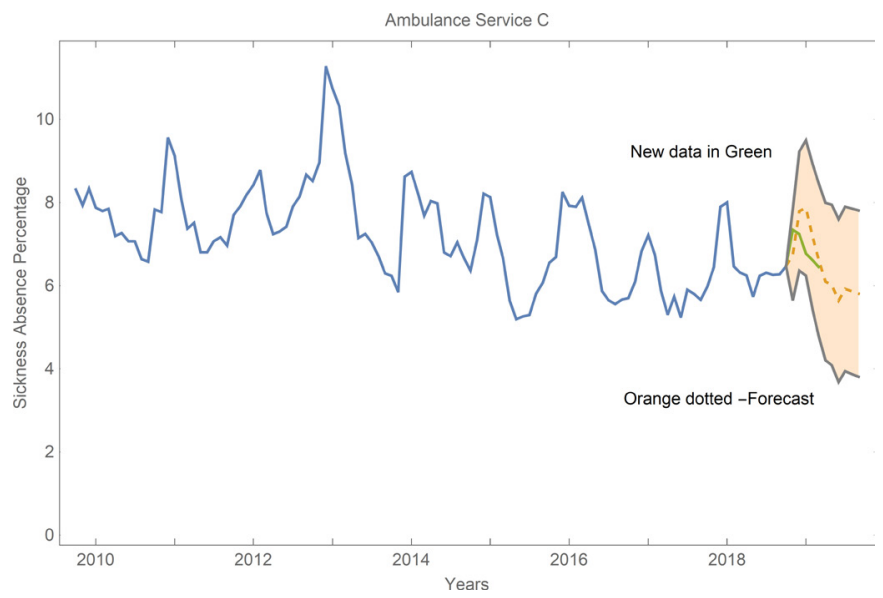

Figure 5 Sickness absence rates over time (2009-2018) with forecast (orange line) and actual rates for 2019 (solid blue and green line) for ambulance service $C$. The shaded area represents the $95 \%$ forecast Cls for 12 months prediction. 
Ambulance Service A

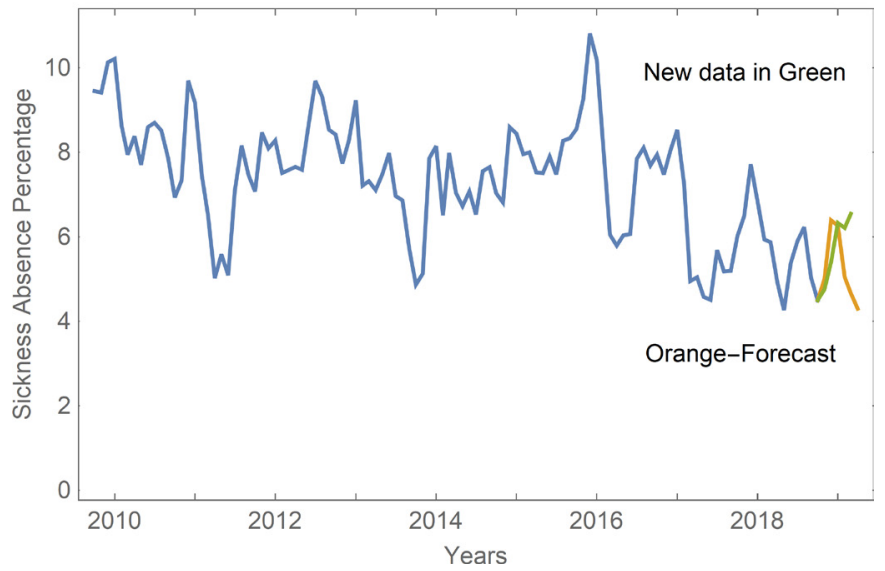

Figure 6 Sickness absence rates over time (2009-2018) with forecast (orange line) and actual rates for 2019 (blue and green solid lines) for ambulance service A.

found one exercise (Tai Chi), one multicomponent (policy, exercise, psychosocial and workplace review) and an influenza vaccination intervention were effective but four other trials (including one influenza vaccination, two multicomponent and a process consultation designed to enhance relationships between managers and staff) showed no effect. Workplace counselling including to healthcare workers has been shown to reduce sickness absence. ${ }^{26}$ A systematic review of whole system approaches, suggests that a combination of identifying and response to local need, engaging staff and leaders, and management and board-level training improve well-being. ${ }^{27}$

Future research should investigate reasons for the twofold variation in sickness absence rates among ambulance services and whether differences might be explained by differences in organisational culture, management support, well-being provision or other factors.

In conclusion, we demonstrated that seasonality plays a key role in determining the extent of sickness absence in the ambulance service. The models have sufficient predictive capability to help ambulance trusts plan for periods

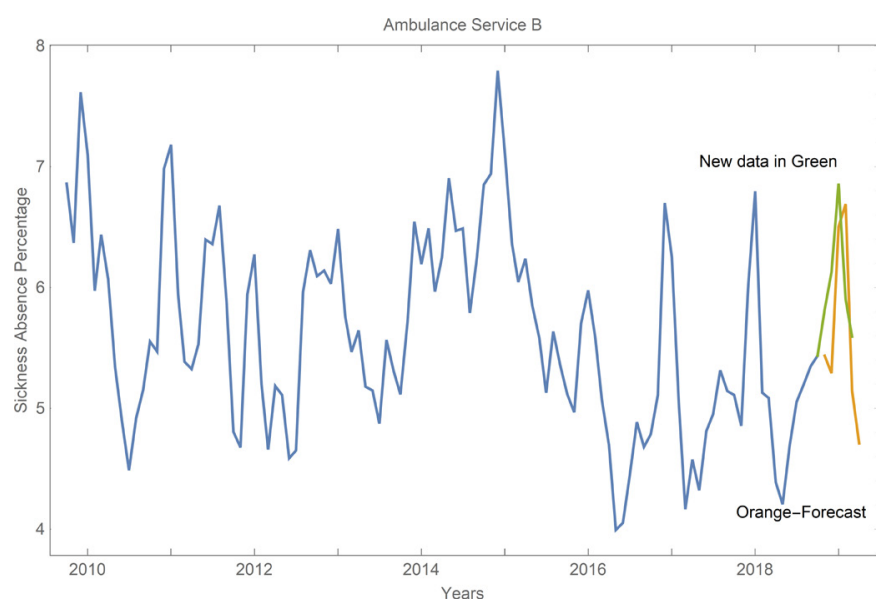

Figure 7 Sickness absence rates over time (2009-2018) with forecast (orange line) and actual rates for 2019 (blue and green solid lines) for ambulance service B.
Ambulance Service J

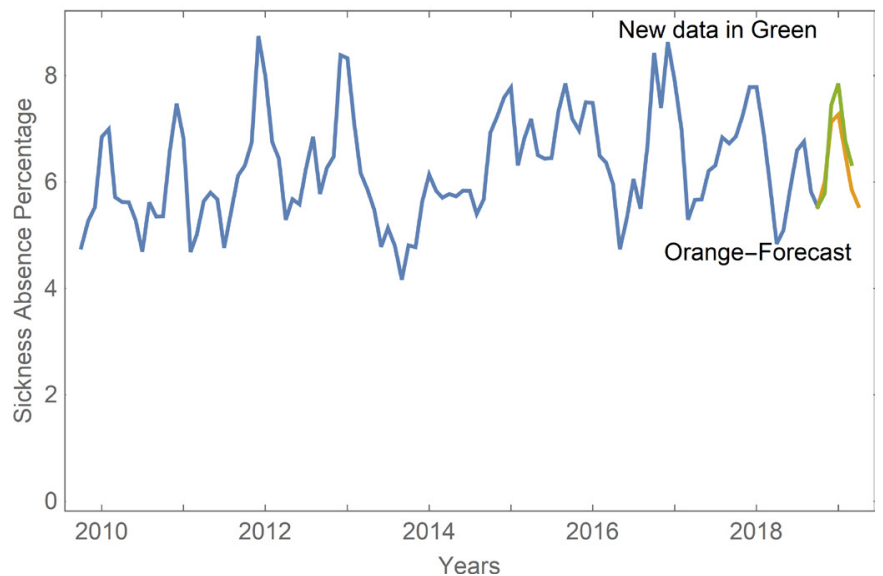

Figure 8 Sickness absence rates over time (2009-2018) with forecast (orange line) and actual rates for 2019 (blue and green solid lines) for ambulance service J.

of increased absence which coincide with increased winter demands on the service. Predictive models may help to forecast sickness absence in a wider variety of health settings, leading to resource planning and potential financial savings.

Twitter Zahid B Asghar @zbasghar, Viet-Hai Phung @VietHaiPhung and Aloysius Niroshan Siriwardena @nsiriwardena

Contributors ZBA wrote the first draft and analysed the data. He conceptualised the study and methodology, conducted formal analyses, drafted the original version of the manuscript with PW and was involved in all manuscript revisions leading to submission. PW and FB obtained the data. ANS, FB, PW, ZBA and KS supervised the study. ZBA, ANS, PW, FB, KH and V-HP were involved in manuscript revisions leading to submission.

Funding Health Education England Ref: A012012019.

Disclaimer The funders had no role in this study.

Competing interests None declared.

Patient consent for publication Not applicable.

Ethics approval Ethical approval for the study was obtained through University of Lincoln REC (Ref: 2019-Aug-0723), no Health Research Authority Approval was sought. Participant consent was deemed not to be required for the use of these data.

Provenance and peer review Not commissioned; externally peer reviewed.

Data availability statement Data are available on reasonable request. Data are available on reasonable request from NHS digital.

Supplemental material This content has been supplied by the author(s). It has not been vetted by BMJ Publishing Group Limited (BMJ) and may not have been peer-reviewed. Any opinions or recommendations discussed are solely those of the author(s) and are not endorsed by BMJ. BMJ disclaims all liability and responsibility arising from any reliance placed on the content. Where the content includes any translated material, BMJ does not warrant the accuracy and reliability of the translations (including but not limited to local regulations, clinical guidelines, terminology, drug names and drug dosages), and is not responsible for any error and/or omissions arising from translation and adaptation or otherwise.

Open access This is an open access article distributed in accordance with the Creative Commons Attribution Non Commercial (CC BY-NC 4.0) license, which permits others to distribute, remix, adapt, build upon this work non-commercially, and license their derivative works on different terms, provided the original work is properly cited, appropriate credit is given, any changes made indicated, and the use is non-commercial. See: http://creativecommons.org/licenses/by-nc/4.0/.

ORCID iDs

Zahid B Asghar http://orcid.org/0000-0003-2564-2096 
Kristy Sanderson http://orcid.org/0000-0002-3132-2745

Aloysius Niroshan Siriwardena http://orcid.org/0000-0003-2484-8201

\section{REFERENCES}

1 Digital N. NHS sickness absence rates January 2019 to March 2019 and annual summary 2010-11 to 2018-19. Department of health and social care. London: Digital N, 2019.

2 Carter L. Operational productivity and performancein English NHS ambulance trusts: unwarranted variations, 2018. Available: https:// www.gov.uk/government/publications/productivity-in-nhs-hospitals

3 Boorman S. NHS health and well-being review: interim report (London). Department of Health 2009.

4 Stilwell JA, Stilwell PJ. Sickness absence in an ambulance service. $J$ Soc Occup Med 1984;34:96-9.

5 Simmons L, Jones AW, Siriwardena N, et al. Interventions to reduce sickness absence among healthcare workers: a systematic review. International Journal of Emergency Services 2019;8:147-62.

6 Wankhade P. Staff perceptions and changing role of pre-hospital profession in the UK ambulance services. International Journal of Emergency Services 2016;5:126-44.

7 Baydoun M, Dumit N, Daouk-Öyry L. What do nurse managers say about nurses' sickness absenteeism? a new perspective. J Nurs Manag 2016;24:97-104.

8 Sterud T, Hem E, Lau B, et al. A comparison of general and ambulance specific stressors: predictors of job satisfaction and health problems in a nationwide one-year follow-up study of Norwegian ambulance personnel. Journal of Occupational Medicine and Toxicology 2011;6:10-19.

9 Mars B, Hird K, Bell F, et al. Suicide among ambulance service staff: a review of coroner and employment records. Br Paramed $J$ 2020;4:10-15.

10 Mind. Blue light programme research summary 2016-18. London 2018.

11 Farmer P, Stevenson D. Thriving at work: the independent review of mental health and employers. Retrieved January;20:2018, 2017. Available: https://assetspublishingservicegovuk/government/ uploads/system/uploads/attachment_data/file/658145/thriving-atwork-stevenson-farmer-reviewpdf

12 Park YS, Konge L, Artino AR. The Positivism paradigm of research. Acad Med 2020;95:690-4.

13 Zhang X, Zhang T, Young AA, et al. Applications and comparisons of four time series models in epidemiological surveillance data. PLOS One 2014;9:e88075.
14 Luo L, Luo L, Zhang X, et al. Hospital daily outpatient visits forecasting using a combinatorial model based on ARIMA and Ses models. BMC Health Serv Res 2017;17:469.

15 Moberly T. Sickness absence rates across the NHS. BMJ 2018;361:k2210.

16 Spears DR, McNeil C, Warnock E, et al. Predicting temporal trends in sickness absence rates for civil service employees of a federal public health agency. J Occup Environ Med 2013;55:179-90.

17 Edwards CH, Tomba GS, Sonbo Kristiansen I, et al. Evaluating costs and health consequences of sick leave strategies against pandemic and seasonal influenza in Norway using a dynamic model. BMJ Open 2019;9:e027832.

18 Verow P, Hargreaves C. Healthy workplace indicators: costing reasons for sickness absence within the UK National health service. Occup Med 2000;50:251-7.

19 Friedenberg R, Kalichman L, Ezra D, et al. Work-related musculoskeletal disorders and injuries among emergency medical technicians and paramedics: a comprehensive narrative review. Arch Environ Occup Health 2020:1-9.

20 Jones S. Describing the mental health profile of first responders: a systematic review. J Am Psychiatr Nurses Assoc 2017;23:200-14.

21 Kyron MJ, Rikkers W, LaMontagne A, et al. Work-related and nonwork stressors, PTSD, and psychological distress: prevalence and attributable burden among Australian police and emergency services employees. Psychol Trauma 2019. doi:10.1037/tra0000536. [Epub ahead of print: 02 Dec 2019].

22 Danial J, Cepeda JA, Cameron F, et al. Epidemiology and costs associated with norovirus outbreaks in NHS Lothian, Scotland 2007-2009. Journal of Hospital Infection 2011;79:354-8.

23 Holt M, Powell S. Health and well-being in small and medium-sized enterprises (SMEs). what public health support do SMEs really need? Perspect Public Health 2015;135:49-55.

24 Imai C, Toizumi M, Hall L, et al. A systematic review and metaanalysis of the direct epidemiological and economic effects of seasonal influenza vaccination on healthcare workers. PLoS One 2018;13:e0198685

25 Ishimaru T, Kubo T, Honno K, et al. Near misses and presenteeism among paramedics. Occup Med 2019;69:593-7.

26 McLeod J. The effectiveness of workplace counselling: a systematic review. Couns Psychother Res 2010;10:238-48.

27 Brand SL, Thompson Coon J, Fleming LE, et al. Whole-system approaches to improving the health and wellbeing of healthcare workers: a systematic review. PLoS One 2017;12:e0188418. 